\title{
Additional mechanical pleurodesis after thoracoscopic wedge resection and covering procedure for primary spontaneous pneumothorax
}

\author{
Sukki Cho $\cdot$ Kyoung-Min Ryu $\cdot$ Sanghoon Jheon $\cdot$ Sook-Whan Sung $\cdot$ \\ Byung-Ho Kim · Dong Myung Huh
}

Received: 27 March 2008/ Accepted: 23 June 2008/Published online: 19 September 2008

(C) Springer Science+Business Media, LLC 2008

\begin{abstract}
Background Additional mechanical pleurodesis for the treatment of primary spontaneous pneumothorax (PSP) is believed to reduce the recurrence of PSP, and a covering procedure with absorbable mesh also shows comparable results. This study was conducted to determine whether additional mechanical pleurodesis would be effective in reducing recurrence after thoracoscopic wedge resection and covering procedure.

Materials and methods Between May 2003 and August 2005, 99 patients underwent thoracoscopic bullectomy with staple line covering with absorbable cellulose mesh and fibrin glue followed by an additional mechanical pleurodesis. These patients were compared with 98 patients who underwent thoracoscopic bullectomy with staple line coverage alone.

Results The additional mechanical pleurodesis group had findings comparable to those of the coverage group for duration of postoperative chest drainage, length of hospital
\end{abstract}

S. Cho $\cdot$ K.-M. Ryu $\cdot$ S. Jheon $\cdot$ S.-W. Sung

Department of Thoracic and Cardiovascular Surgery,

Seoul National University, Bundang Hospital, Gyeonggi-do,

South Korea

S. Cho

e-mail: skcho@knu.ac.kr

S. Jheon $(\bowtie) \cdot$ S.-W. Sung

Department of Thoracic and Cardiovascular Surgery, College of Medicine, Seoul National University, 28 Yeongeon-Dong,

Jongro-Gu, Seoul 110-744, South Korea

e-mail: Jheon@snu.ac.kr

B.-H. Kim · D. M. Huh

Department of Thoracic and Cardiovascular Surgery,

Daegu Fatima Hospital, Daegu, South Korea stay, and complication rate. After median follow-up of 29.2 months, postoperative recurrence occurred in four patients $(4.0 \%)$.

Conclusions Additional mechanical pleurodesis after covering procedure is also effective in decreasing postoperative recurrence of PSP.

Keywords Primary spontaneous pneumothorax (PSP) . Mechanical pleurodesis - Video-assisted thoracic surgery (VATS)

Primary spontaneous pneumothorax (PSP) is well known to have high recurrence rates if not treated appropriately. There are ongoing debates on how to most effectively lower its recurrence after the first clinical treatment. Conservative treatments, such as needle aspiration or pleural drainage with a chest tube, show rather high recurrence rates, varying from $11 \%$ up to $36 \%$ [1]. Active surgical operations using thoracoscopy have resulted in a significant reduction in overall morbidity. However, wedge resection alone by video-assisted thoracoscopic surgery (VATS) has caused some doubts due to the high recurrence rates, hence various pleural symphyses have been performed in order to reduce its recurrence rate. In a previous retrospective study, Sakamoto et al. found that a staple line coverage procedure, which helps reduce the recurrence rate by minimizing the formation of new blebs near the staple line, showed a recurrence rate comparable to that of pleural symphysis, and as a result it has been confirmed that this procedure is effective in decreasing the recurrence rate of PSP [2, 3].

In this context, some questions have been raised as to whether additional mechanical pleurodesis can further reduce the recurrence rate if performed simultaneously 
along with staple line coverage. Thus, this study examined whether additional mechanical pleurodesis combined with the staple line coverage procedure significantly reduces postoperative recurrence.

\section{Materials and methods}

\section{Patients}

From May 2003 to August 2005, 99 patients underwent thoracoscopic bullectomy with coverage procedure and mechanical pleurodesis in the Division of Thoracic Surgery of Seoul National University Bundang Hospital (SNUBH) and Daegu Fatima Hospital. Eligibility criteria included ipsilateral or bilateral recurrent pneumothorax, history of previous contralateral pneumothorax, visible blebs on the initial chest plain film, or persistent air leakage for more than 5 days. The exclusion criteria were underlying pulmonary disease such as pulmonary tuberculosis, more than 50 years of age, previous ipsilateral thoracic operation, and refusal to undergo the study. These patients were compared with 98 patients who underwent thoracoscopic bullectomy with coverage of staple line with absorbable mesh and fibrin glue alone. The primary endpoint was the rate of ipsilateral recurrence after operation. This study was conducted after permission was obtained from the IRB of SNUBH and Daegu Fatima Hospital. All patients provided written informed consent.

\section{Operative techniques}

All patients were operated on under general anesthesia by a thoracic surgeon. A double-lumen endotracheal tube was used. Patients were placed in the lateral decubitus position. If a chest tube was in place before the operation, it was removed before preparation and draping. The first trocar $(10 \mathrm{~mm})$ for a thoracoscope was placed in the seventh intercostal space at the midaxillary line. After introducing a 10 -mm thoracoscope with a $30^{\circ}$ lens, a second trocar $(11.5 \mathrm{~mm})$ was placed for an endoscopic stapling device in the fourth intercostal space at the anterior axillary line, and a third trocar $(5 \mathrm{~mm})$ for endoscopic forceps was placed in the fifth intercostal space at the posterior axillary line. After a thorough examination of the entire visceral pleural surface, blebs were resected using an endoscopic stapling device: either an Autosuture GIA Universal ${ }^{\circledR}$ (Tycohealthcare, Norwalk, CT, USA) or an Endopath ETS45 ${ }^{\circledR}$ (Ethicon Endo-Surgery, Cincinnati, OH, USA), according to the surgeon's preference. Special care was taken to place staple lines on normal lung tissue so as not to include blebs. In cases with no blebs or suspicious subpleural blebs, blind apical stapling was done. Saline solution was injected into the pleural cavity and the lung was ventilated to identify the air leak. If no air leak was found, staple lines were covered with absorbable cellulose mesh (Surgicel ${ }^{\circledR}$; Johnson and Johnson, Sommerville, NJ, USA) while inflated along with fibrin glue (TISSEEL ${ }^{\circledR}$, Baxter, Deerfield, IL, USA). After wedge resection and coverage procedures, patients received an additional mechanical pleurodesis. Mechanical pleurodesis was performed by scrubbing the parietal pleura with a swab of Vicryl mesh (Johnson and Johnson, Sommerville, NJ, USA) mounted on the tip of either an endoscopic curved grasping forceps or a curved ring forceps inserted into the chest cavity through the port sites. Vigorous pleural abrasion was performed until uniform oozing of the pleura was obtained. The pleural abrasion limits were from the apex down to the fifth intercostal space, the internal thoracic artery anteriorly, and the sympathetic chain posteriorly.

\section{Postoperative care}

A chest tube was placed through the camera port site in order to verify adequate lung re-expansion. If the lung was not fully expanded on immediately checked chest radiography, the chest tube was connected to a low-pressure (about $15 \mathrm{cmH}_{2} \mathrm{O}$ ) suction system. This chest tube was usually removed when any pulmonary parenchymal air leak had resolved, when lung was totally re-expanded, and when pleural drainage was less than $100 \mathrm{ml}$ per $24 \mathrm{~h}$. Patients were discharged on the day after removal of chest tube, if there was no sign of pneumothorax on chest radiography.

\section{Follow-up}

After being discharged from the hospital, patients received follow-up care at an outpatient clinic at 1 week, 6 months, and 12 months, at which time a chest radiography was performed. All patients received follow-up care for at least 12 months. Patients were instructed to visit a clinic or emergency room whenever they had any signs related to the recurrence of pneumothorax, such as chest pain, cough, or dyspnea.

\section{Data collection and statistical analysis}

Clinical data, operative findings, and data on the duration of postoperative chest tube drainage, length of hospital day, and complications were collected. Continuous variables were expressed as means \pm standard deviation (SD) and analyzed by a two-sample $t$-test. Categorical variables were expressed by frequency and analyzed by chi-square test. Freedom from recurrence was analyzed by the KaplanMeier method and comparisons were made by a log-rank 
test. A two-sided $p$ value of less than 0.05 was considered statistically significant.

\section{Results}

Table 1 lists and compares baseline clinical characteristics for patients with and without additional mechanical pleurodesis. There were no significant differences between the two groups. The additional mechanical pleurodesis group had comparable findings to the coverage group with regard to duration of postoperative chest drainage, length of hospital stay, and complication rate (Table 2). There were no deaths during or after operation and no conversion to thoracotomy. There was one case of bleeding at the port site in the additional mechanical pleurodesis group, but its cause was not related to mechanical pleurodesis. No surgical reoperation has been observed in patients who were experiencing constant air leaks; all patients were discharged after removal of the chest tube within 7 days. Median follow-up was 29.0 (range 12-42) months in the additional mechanical pleurodesis group, and 29.4 (range 13-45) months in the coverage group. During postoperative follow-up, recurrences occurred in four patients $(4.0 \%)$ in the additional mechanical pleurodesis group and in five patients $(5.1 \%)$ in the coverage group (log-rank test, $p=0.714)$. Recurrence of pneumothorax was managed in a variety of ways (Table 3 ). Three patients (one in the additional mechanical pleurodesis group and two in the coverage group) with small $(<10 \%)$ loculated pneumothorax were observed and the others with more than $20 \%$ pneumothorax were treated with a 7Fr mini chest tube.

Table 1 Clinical characteristics of patients with and without additional mechanical pleurodesis

\begin{tabular}{|c|c|c|c|}
\hline Characteristic & $\begin{array}{l}\text { Mechanical } \\
\text { pleurodesis } \\
(n=99)\end{array}$ & $\begin{array}{l}\text { Coverage } \\
(n=98)\end{array}$ & $p$-value \\
\hline Age, years ${ }^{\mathrm{a}}$ & $24.9 \pm 10.8$ & $23.1 \pm 7.9$ & 0.182 \\
\hline Male $(\%)$ & $89(89.9)$ & $86(87.8)$ & 0.633 \\
\hline Smoker $(\%)$ & $41(41.4)$ & $28(28.6)$ & 0.059 \\
\hline Pneumothorax site & & & 0.937 \\
\hline Right & 48 & 45 & \\
\hline Left & 50 & 52 & \\
\hline Both & 1 & 1 & \\
\hline Surgical indications & & & 0.839 \\
\hline Ipsilateral recurrence & 30 & 32 & \\
\hline Contralateral recurrence & 16 & 19 & \\
\hline Visible blebs & 81 & 74 & \\
\hline Persistent air leak $\geq 5$ days & 8 & 12 & \\
\hline Other & 5 & 7 & \\
\hline
\end{tabular}

${ }^{a}$ Values represent means $\pm \mathrm{SD}$
Table 2 Results of treatment of patients with and without additional mechanical pleurodesis

\begin{tabular}{|c|c|c|c|}
\hline & $\begin{array}{l}\text { Mechanical } \\
\text { pleurodesis } \\
(n=99)\end{array}$ & $\begin{array}{l}\text { Coverage } \\
(n=98)\end{array}$ & $p$-value \\
\hline $\begin{array}{l}\text { Postoperative chest tube duration } \\
\text { (days) }^{\mathrm{a}}\end{array}$ & $1.9 \pm 1.8$ & $1.7 \pm 1.8$ & 0.424 \\
\hline $\begin{array}{l}\text { Postoperative hospital stay } \\
{(\text { (days })^{\mathrm{a}}}\end{array}$ & $3.5 \pm 1.8$ & $3.2 \pm 2.0$ & 0.335 \\
\hline Complications, no. (\%) & $14(14.1)$ & $14(14.3)$ & 0.841 \\
\hline Air leak $>5$ days, no. $(\%)$ & $5(5.1)$ & $7(7.1)$ & \\
\hline Pleural detachment, no. $(\%)^{\mathrm{b}}$ & $6(6.1)$ & $5(5.1)$ & \\
\hline Effusion, no. $(\%)^{\mathrm{c}}$ & $2(2.0)$ & $2(2.0)$ & \\
\hline $\begin{array}{l}\text { Bleeding (reoperation), } \\
\text { no. }(\%)\end{array}$ & $1(1.0)$ & $0(0)$ & \\
\hline
\end{tabular}

Two of six patients with persistent air leak (one in each group) were treated by repeat VATS. For one patient in the coverage group, recurrence occurred 2 months after the operation, and there was loose adhesion between parietal and visceral pleura, and ruptured bleb was found on the margin of the covered area. Wedge resection and coverage procedure were then performed. For another patient in the additional mechanical pleurodesis group, recurrence occurred 4 months after the operation, and focal fibrous adhesion were observed on the lateral side of upper thorax where the previous pleurodesis had been performed and easily divided. Because there was no definite ruptured bleb, suspicious area was resected, and coverage and additional

Table 3 Postoperative recurrence of pneumothorax

\begin{tabular}{|c|c|c|c|c|c|}
\hline No. & Group $^{a}$ & $\begin{array}{l}\text { Interval of } \\
\text { recurrence } \\
\text { (months) }\end{array}$ & $\begin{array}{l}\text { Amount of } \\
\text { pneumothorax } \\
(\%)\end{array}$ & Treatment $^{\mathrm{b}}$ & $\begin{array}{l}\text { Second } \\
\text { operative } \\
\text { findings }\end{array}$ \\
\hline 1 & $\mathrm{C}$ & 4 & $<10$ & $\mathrm{O}_{2}$ & \\
\hline 2 & $\mathrm{C}$ & 2 & $<10$ & $\mathrm{O}_{2}$ & \\
\hline 3 & $\mathrm{C}$ & 1 & 30 & $7 \mathrm{Fr}$ & \\
\hline 4 & $\mathrm{C}$ & 2 & 50 & Operation & $\begin{array}{l}\text { Bleb near } \\
\text { staple line }\end{array}$ \\
\hline 5 & $\mathrm{C}$ & 9 & 20 & 7Fr & \\
\hline 6 & M & 4 & 50 & Operation & $\begin{array}{l}\text { No definite } \\
\text { ruptured } \\
\text { bleb }\end{array}$ \\
\hline 7 & M & 3 & $<10$ & $\mathrm{O}_{2}$ & \\
\hline 8 & M & 16 & 30 & $7 \mathrm{Fr}$ & \\
\hline 9 & M & 5 & 30 & $7 \mathrm{Fr}$ & \\
\hline
\end{tabular}


Table 4 Recurrence rates in studies of the thoracoscopic treatment of primary spontaneous pneumothorax

\begin{tabular}{llllll}
\hline Author (ref.) & Year & Patients & Additional procedures & Recurrence (\%) & Follow-up (months) \\
\hline Bertrand [18] & 1996 & 163 & Abrasion & 3.7 & 24.5 \\
Yim [19] & 1997 & 518 & Abrasion & 1.7 & 20 \\
Maier [17] & 2000 & 41 & Abrasion & 2.1 & 36 \\
Ayed [8] & 2000 & 72 & Pleurectomy, abrasion & 5.5 & 42 \\
Cardillo [9] & 2000 & 432 & Pleurectomy, talc insufflation & 4.4 & 38 \\
Horio [7] & 2002 & 53 & Coagulation & 1.9 & 38 \\
Gossot [12] & 2004 & 185 & Abrasion & 3.6 & 36.5 \\
Sakamoto [2] & 2004 & 114 & Mesh coverage & 2.6 & 25 \\
Jheon [3] & 2005 & 219 & Mesh/glue coverage & 4.8 & 29 \\
Chen [13] & 2006 & 103 & Chemical pleurodesis & 1.9 & 29 \\
\hline
\end{tabular}

mechanical pleurodesis were performed. There was no recurrence among the reoperated patients.

\section{Discussion}

Primary spontaneous pneumothorax (PSP) is a relatively common disease and causes mental stress in young men due to fear of recurrence. Without adequate treatment, estimates of the recurrence rate after a first episode range from $10 \%$ to $21 \%$; after a second episode, it is estimated to be close to 50\%; and it is almost $80 \%$ after a third episode $[4,5]$. Thus, it is agreed that the surgical approach utilized should minimize recurrence, but there is no agreement about the best procedure to perform: axillary thoracotomy, thoracoscopic bullectomy with or without pleurectomy, or mechanical pleurodesis. Over the past decade, many articles have been published with the conclusion that VATS has definitely proved to be the standard of treatment for PSP. However, initial enthusiasm has been tempered by high recurrence rates and the high cost of treatment due to the use of endostaplers and video equipment [6]. A simple thoracoscopic bullectomy using an endostapler has a relatively high postoperative recurrence rate of up to $16 \%$ [7]. Therefore, several methods have been attempted for the symphysis of pleura after excising blebs in order to reduce the rate of recurrence. Several methods of pleurodesis, including pleurectomy $[8,9]$, pleural abrasion [10-12], and chemical pleurodesis $[13,14]$, have been performed. As shown in Table 4, each procedure yielded good results in preventing the postoperative recurrence. However, considering that the pathophysiology of PSP originates in visceral pleura, it was obvious that the pleural symphysis whatever the method has caused normal pleural physiology disturbance. To compensate for these disadvantages, a coverage procedure after the thoracoscopic bullectomy was introduced. Sakamoto et al. reported performance of staple line coverage with an absorbable mesh in 114 patients over a 3-year period with a recurrence rate of only $2.6 \%$ in the coverage group and $9.5 \%$ in the simple bullectomy group [2]. Kurihara et al. combined the absorbable cellulose mesh with fibrin glue to a staple line and reduced the recurrence rate [15]. One of the reasons for postoperative recurrence is reportedly the formation of new blebs near the staple line and this is confirmed by the observation of patients who undergo reoperation [2]. In addition, postoperative air leaks occur mainly at the staple line, as a result of stapling problems, incomplete resection of blebs, emphysematous changes in the resected area, or the crossing of the staple line [16]. Therefore, the reinforcement of visceral pleura around the staple line appears to be a reasonable approach to prevent postoperative air leaks and postoperative recurrence. The authors previously conducted a similar study on 219 patients using absorbable cellulose mesh and fibrin glue after a bullectomy and reported a $4.8 \%$ recurrence rate after median follow-up of 46 months [3]. This result itself might be satisfactory and then to evaluate the effect of additional mechanical pleurodesis on covering procedure. This study showed a $4.0 \%$ postoperative recurrence rate, but did not significantly decrease postoperative recurrence. There are several reasons why this occurred. First, this is probably due to the pleurodesis technique used, in which the mechanical pleurodesis limits are from the apex of thorax to the fifth intercostal space. Because ruptured blebs are mostly confined to the upper lobe, mechanical pleurodesis such as that used in this technique might be sufficient to obliterate the upper lung fields. Horio et al. and Maier et al. also showed satisfactory results with limited mechanical pleurodesis, however apical partial pleurectomy alone will not prevent recurrence in the lower part of the chest $[7,17]$. If complete apical pleurectomy by abrading the lower parietal pleura is performed, the recurrence rate is significantly reduced [12]. Second, it is possible that the presence of foreign material such as absorbable mesh and fibrin glue on the visceral pleura in this study may make mechanical pleurodesis less 
effective. Considering that the success of pleural symphysis depends on the time which it takes to attach the visceral pleura to parietal pleura, the covering procedure might be a disturbing factor. However, this covering procedure is not thought to seriously affect the results because the extent of mechanical pleurodesis is larger than that of the coverage procedure. From the results of the present study, it was concluded that additional mechanical pleurodesis after the coverage procedure is also effective in decreasing the recurrence rate. Although this study is thought to be a good trial, the conclusion will be clarified after further large-scale study is conducted.

Acknowledgements This paper was presented orally at the 1 st ELSA meeting in Seoul, Korea, 2006.

\section{References}

1. Schramel FM, Sutedja TG, Braber JC, van Mourik JC, Postmus PE (1996) Cost-effectiveness of video-assisted thoracoscopic surgery versus conservative treatment for first time or recurrent spontaneous pneumothorax. Eur Respir J 9:1821-1825

2. Sakamoto K, Takei H, Nishii T, Maehara T, Omori T, Tajiri M, Imada $\mathrm{T}$ et al (2004) Staple coverage with absorbable mesh after thoracoscopic bullectomy for spontaneous pneumothorax. Surg Endosc 18:478-481

3. Cho S, Huh DM, Kim BH, Lee S, Kwon OC, Ahn WS, Jheon S (2008) Staple line covering procedure after thoracoscopic bullectomy for the management of primary spontaneous pneumothorax. Thorac Cardiovasc Surg 56:217-220

4. Inderbitzi RGC, Leiser A, Furrer M, Althaus U (1994) Three years experience in video-assisted thoracic surgery (VATS) for spontaneous pneumothorax. J Thorac Cardiovasc Surg 107:1410 1415

5. Cran IR, Rumball CA (1967) Survey of spontaneous pneumothorax in the Royal air force. Thorax 22:462-465

6. Massard G, Thomas P, Wihlm JM (1998) Minimally invasive management for first and recurrent pneumothorax. Ann Thorac Surg 66:592-599

7. Horio H, Nomori H, Kobayashi R, Naruke T, Suemasu K (2002) Impact of additional pleurodesis in video-assisted thoracoscopic bullectomy for primary spontaneous pneumothorax. Surg Endosc 16:630-634

8. Ayed AK, Al-Din HJ (2000) The results of thoracoscopic surgery for primary spontaneous pneumothorax. Chest 118:235-238

9. Cardillo G, Facciolo F, Giunti R, Gasparri R, Lopergolo M, Orsetti R, Martelli M (2000) Videothoracoscopic treatment of primary spontaneous pneumothorax: a 6-year experience. Ann Thorac Surg 69:357-361

10. Chan P, Clarke P, Daniel FJ, Knight SR, Seevanayagam S (2001) Efficacy study of video-assisted thoracoscopic surgery pleurodesis for spontaneous pneumothorax. Ann Thorac Surg 71:452454

11. Lang-Lazdunski L, Chapuis O, Bonnet PM, Pons F, Jancovici R (2003) Videothoracoscopic bleb excision and pleural abrasion for the treatment of primary spontaneous pneumothorax: long-term results. Ann Thorac Surg 75:960-965

12. Gossot D, Galetta D, Stern JB, Debrosse D, Caliandro R, Girard P, Grunenwald D (2004) Results of thoracoscopic pleural abrasion for primary spontaneous pneumothorax. Surg Endosc 18:466-471

13. Chen JS, Hsu HH, Chen RJ, Kuo SW, Huang PM, Tsai PR, Lee JM et al (2006) Additional minocycline pleurodesis after thoracoscopic surgery for PSP. Am J Respir Crit Care Med 173:548554

14. de Campos JR, Vargas FS, de Campos Werebe E, Cardoso P, Teixeira LR, Jatene FB, Light RW (2001) Thoracoscopy talc poudrage: a 15-year experience. Chest 119:801-806

15. Kurihara M, Takeno Y (1999) Thoracoscopic surgery for pneumothorax and its recurrence after thoracoscopic surgery. Asian J Surg 22:9-14

16. Hatz RA, Kaps MF, Meimarakis G, Loehe F, Muller C, Furst H (2000) Long term results after video-assisted thoracoscopic surgery for first time and recurrent spontaneous pneumothorax. Ann Thorac Surg 70:253-257

17. Maier A, Anegg U, Renner H, Tomaselli F, Fell B, Lunzer R, Sankin O et al (2000) Four-year experience with pleural abrasion using a rotating brush during video-assisted thoracoscopy. Surg Endosc 14:75-78

18. Bertrand PC, Regnard JF, Spaggiari L, Levi JF, Magdeleinat P, Guibert L, Levasseur P (1996) Immediate and long-term results after surgical treatment of primary spontaneous pneumothorax by VATS. Ann Thorac Surg 61:1641-1645

19. Yim APC, Lin HP (1997) Video assisted thoracoscopic management of primary spontaneous pneumothorax. Surg Laparosc Endosc 7:236-240 